\title{
ARÁBIA SAUDITA E IRÃ: RIVALIDADE E DISPUTA PELA HEGEMONIA NO GOLFO PÉRSICO
}

\author{
Beatriz Pidone Costa ${ }^{1}$
}

\begin{abstract}
Resumo
O sectarismo religioso, considerado como um dos principais motivos que levaram à disputa entre Arábia Saudita e Irã, é utilizado como instrumento político por esses Estados em prol de seus interesses. As relações entre ambos tiveram um início cooperativo, porém, após a Revolução Iraniana de 1979, passaram apenas a se deteriorar. O embate entre os países islâmicos se acirrou, impulsionado pelas intervenções americanas na região, pela Primavera Árabe e, pela crise de legitimidade dos governos islâmicos. Atualmente, sem perspectivas de reatamento, as relações diplomáticas entre os países encontram-se rompidas. Enquanto o Irã vem ganhando espaço e influência, apesar de sérios problemas internos, a Arábia Saudita, mesmo com força regional e novas estratégias para sua política externa e interna, se vê prejudicada e enfraquecida.
\end{abstract}

Palavras-chave: Arábia Saudita, Irã, Golfo Pérsico, rivalidade, hegemonia.

\begin{abstract}
Religious sectarianism, considered one of the main reasons that led to the dispute between Saudi Arabia and Iran, is used as a political instrument by these states for their interests. The relations between them had a cooperative beginning, but after the Iranian Revolution in 1979, they only deteriorated. The clash between Islamist countries has stirred up, boosted by US interventions in the region, by the Arab Spring and, by the legitimacy crisis of Islamic governments. Currently, with no prospect of reattachment, the diplomatic ties of both countries remain severed. While Iran has been gaining space and influence, despite serious internal problems; Saudi Arabia, even with regional strength and new strategies for its foreign and domestic policy, feels undermined and weakened.
\end{abstract}

Keywords: Saudi Arabia, Iran, Persian Gulf, rivalry, hegemony.

\footnotetext{
${ }^{1}$ Universidade Federal do ABC. E-mail: beatriz.pidone@gmail.com. 


\section{Introdução}

O Oriente Médio há muitos anos é palco de diversas disputas e conflitos motivados por questões domésticas, regionais ou estrangeiras. Em sua história recente, mostra-se como um local de extrema importância estratégica para a geopolítica, devido às grandes reservas de petróleo do Golfo Pérsico - região que separa a Arábia Saudita e o Irã.

Um momento importante para a rica história dessa região foi a Revolução Iraniana de 1979, baseada em ideais religiosos e contra a ocidentalização do Oriente Médio. Dessa forma, devido a mudanças tão drásticas, o equilíbrio de poder e o sistema de cooperação entre os países islâmicos foram seriamente prejudicados, e a rivalidade entre a Arábia Saudita e o Irã tornou-se crescente. Os principais atores regionais, em busca de influência e hegemonia, passaram a representar lados opostos - política, religiosa e etnicamente. Enquanto a monarquia árabe saudita segue preceitos sunitas e possui apoio estadunidense, o Irã persa é uma república islâmica que segue o xiismo e possui relações próximas à Rússia. Não há enfrentamento militar direto entre ambos os países, porém, diversas guerras "por procuração"

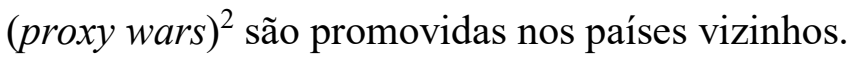

É importante frisar que a guerra religiosa entre sunitas e xiitas não constitui um fim em si mesma, ou seja, não é de interesse de sauditas nem de iranianos fazerem uma limpeza étnica em seus territórios, mas é de interesse desses países que a religião, por seu enorme poder catalisador, seja utilizada como instrumento de radicalização de conflitos no intuito de justificarem as suas medidas através do apelo popular. Desse modo, este trabalho pretende analisar a influência da religião na disputa por hegemonia na região do Golfo Pérsico, bem como o acirramento das relações diplomáticas entre ambos os países em momentos-chave de suas histórias.

\section{Questão religiosa: importante, mas não determinante}

A diferença religiosa entre as duas vertentes islâmicas, a sunita e a xiita, é sempre presente quando se analisam os conflitos no Oriente Médio, e, atualmente, vem ganhando notoriedade, ainda mais no caso do Irã xiita e da Arábia Saudita sunita, cujas populações são de maioria opostas. Domesticamente, pode-se dizer que ambos os governos são sectários e utilizam a religião como forma de legitimar sua autoridade. Entretanto, no âmbito interestatal,

\footnotetext{
${ }^{2}$ Guerras instigadas entre grupos ou Estados mais fracos por Estados potências. Estes não participam efetivamente das guerras, apenas promovem seus interesses ou proveem algum tipo de apoio (econômico, político, diplomático, militar, etc.) aos beligerantes.
} 
a diferença das duas vertentes não pode ser encarada como uma disputa histórica para além de soluções políticas, pois esse sectarismo é aproveitado e manipulado no jogo internacional.

Perhaps the most dangerous oversimplification to come from an un-nuanced acceptance of the "Sunni versus Shia" frame is to misunderstand the motivations of the two major state actors in the regional contest for influence. [...] Riyadh and Tehran are playing a balance of power game. They are using sectarianism in that game, yet their motivations are not centuries-long religious disputes but a simple contest for regional influence. (GAUSE, 2014, p.6) ${ }^{3}$

Além do próprio incentivo estatal, como visto no interior da Arábia Saudita e do Irã, o sectarismo doméstico vem ganhando força em outros países devido às recentes perdas de poder e de legitimidade dos governos, contribuindo ainda mais para o uso do sectarismo nas guerras "por procuração". Como os Estados, em meio a conflitos e guerras, não conseguem suprir as necessidades básicas da população, como alimentação e moradia, há uma tendência das pessoas a se unirem em grupos, muitas vezes baseados religiosa ou etnicamente, fortalecendo assim, a divisão interna da população e facilitando o acirramento do sectarismo no Oriente Médio entre sunitas, xiitas e até mesmo outras etnias e religiões, como os curdos (GAUSE, 2014).

Uma das formas mais eficientes utilizadas por ambos os Estados para disseminar sua influência na região é através da cultura, já que são limitados militarmente por não possuírem poderio suficiente para dominar o rival e, economicamente, pois a Arábia Saudita é dependente da exportação de petróleo, enquanto o Irã, apesar da economia mais diversificada, sofre para superar as sanções e a falta de internacionalização. Dessa forma, difundir ideais políticos, sociais e culturais torna-se essencial. O sectarismo e as divisões da religião islâmica são os fatores que mais influenciam a opinião pública sobre a percepção das potências regionais no Oriente Médio (CIFTCI; TEZCÜR, 2016), o que leva os Estados a buscarem, através do acirramento religioso, tanto o apoio de sua própria população como a de países vizinhos, legitimando suas políticas e expandindo seu domínio e influência. "Furthermore, religiosity is likely to shape public perceptions of foreign powers as state leaders instrumentally use religious messages and images to bolster their international appeal" (idem, p.380) $)^{4}$.

\footnotetext{
${ }^{3}$ Talvez a mais perigosa simplificação resultante de uma aceitação sem nuances do quadro "sunitas versus xiitas" seja mal interpretar as motivações dos dois principais atores estatais na disputa regional por influência. [...] Riade e Teerã jogam com o equilíbrio de poder. Eles estão usando o sectarismo nesse jogo, contudo suas motivações não são disputas religiosas seculares, mas uma simples disputa por influência regional (GAUSE, 2014, p.6, tradução nossa).

${ }^{4}$ Ademais, é provável que a religiosidade molde as percepções públicas sobre as potências estrangeiras ao passo que os líderes dos Estados usam, instrumentalmente, mensagens e imagens religiosas para reforçar seu apelo internacional. (idem, p.380, tradução nossa).
} 
Ademais, quando se analisa os aliados de cada país, a divisão entre as vertentes religiosas também não é uma obrigatoriedade. Um bom exemplo é o apoio do Irã ao Hamas 5 (sunita) e ao Hezbollah ${ }^{6}$ (xiita). Ambos os grupos citados lutam contra a expansão de Israel sobre o território palestino, caracterizando um conflito entre árabes e israelenses que não é necessariamente religioso. O Irã mostra-se como um país que resiste ao imperialismo estadunidense e à agressão israelense, apoiando a criação do Estado da Palestina, mesmo que este se torne um país de maioria sunita, o que, sob a perspectiva do sectarismo puro, não seria algo possível. "Iran's support for Sunni militant groups opposed to Israel illustrate that Iran is more motivated by its identity as the liberator of the Muslim world than its identity as a Shia state" (HAMEED, 2017, p.24)7. Outro caso é a Síria, Estado de maioria sunita que já mantém uma aliança com os iranianos, antes mesmo da revolução de 1979.

Já no caso saudita, o problema encontra-se na dificuldade de manter sua aliança com outros países de maioria sunita, tanto devido às diferentes vertentes dentro do próprio sunismo, quanto por motivos políticos, especialmente após a Primavera Árabe. No Egito, a ascensão da Irmandade Muçulmana vem gerando atritos e dificuldades na relação com os sauditas, que há muitos anos tinham grande apoio egípcio para estabelecerem seu domínio e influência na região. O outro caso mais recente foram as sanções que Riade impôs sobre o Catar, a partir de junho de 2017. Os catari que, assim como os sauditas, são uma monarquia majoritariamente sunita-wahabita, além de terem sido acusados de patrocinar terroristas, receberam duras críticas em relação a sua empresa estatal de telecomunicações, a Al Jazeera, e por terem retomado relações com o Irã, desafiando a monarquia saudita. Analisando novamente através do sectarismo, tal situação não ocorreria.

\footnotetext{
${ }^{5}$ Hamas, cujo nome é um acrônimo para Movimento de Resistência Islâmico, é uma organização de orientação sunita que luta em prol da Palestina e contra a ocupação de Israel na Faixa de Gaza e Cisjordânia. Após a primeira intifada em 1987, o grupo surgiu com propósitos militar e belicoso, cujas ações o levou a ser considerado como um grupo terrorista fundamentalista por diversos países, como Estados Unidos, Reino Unido e Israel. Além da atuação militar, a organização também possui um braço político. Em 2006, o Hamas ganhou eleições parlamentares na Palestina, o que gerou tensões com outro grupo palestino, o Fatah, resultando na divisão do controle político. O Hamas passou a controlar apenas a Faixa de Gaza, enquanto o Fatah manteve controle da Cisjordânia.

${ }^{6}$ Hezbollah, que significa Partido de Deus, surgiu como uma milícia de orientação xiita com a ajuda do Irã, após a ocupação israelense no Líbano em 1980. Além de lutar contra a presença israelense no Oriente Médio, declararam tanto os Estados Unidos quanto a União Soviética como inimigos do islã. Apesar da pressão para se desarmar, o poder militar foi mantido, contribuindo para ser considerado por alguns países como um grupo terrorista fundamentalista. A organização ingressou na política libanesa de forma gradual, tornando-se um partido expressivo, conquistando votos e poder no parlamento, apoiado principalmente pela população xiita.

${ }^{7} \mathrm{O}$ apoio do Irã a grupos militantes sunitas que se opõem a Israel ilustra que o Irã é mais motivado por sua identidade como o libertador do mundo muçulmano do que sua identidade como um Estado xiita. (HAMEED, 2017, p.24, tradução nossa).
} 
Além do mais, se o sectarismo religioso determinasse exclusivamente países ou grupos aliados ou não, o Irã estaria em grande desvantagem em sua busca pela hegemonia no Golfo Pérsico, pois a maioria das populações dos Estados islâmicos é composta de sunitas, assim como a maioria dos Estados possuem governos que tendem ao sunismo, mesmo que haja um número expressivo de xiitas. Logo, o sectarismo existe e é utilizado como instrumento político, porém não é um determinante exclusivo (ou de maior peso) nos conflitos e relações interestatais. "As mentioned above both Iran and Saudi Arabia acts in pursuit of power and they use religion and other tools in order to gain more power" (FADAEE, 2017, p.20) ${ }^{8}$.

\section{Relações entre Arábia Saudita e Irã}

Logo após a Segunda Guerra Mundial, as relações diplomáticas entre a Arábia Saudita e o Irã foram marcadas pela cooperação, quando ambos utilizavam o sistema governamental monárquico e se encontravam numa fase de consolidação e desenvolvimento de seus governos. Logo após a saída britânica dos territórios do Oriente Médio, dentre eles o Irã, a estratégia estadunidense de combater o comunismo, no contexto da Guerra Fria, via-se ameaçada. Assim, os Estados Unidos passaram a apoiar igualmente ambos os países, que se tornaram os pilares gêmeos (twin pillars) da ordem e da estabilidade na região em prol do Ocidente (FADAEE, 2017). Além disso, também prevalecia o interesse dos Estados Unidos em ter fácil acesso às grandes reservas de petróleo localizadas no Golfo Pérsico. Durante o governo do Xá Reza Pahlavi no Irã (1941-1979) houve a Revolução Branca de 1963, caracterizada por reformas socioeconômicas a favor do Ocidente, fato que desagradou parte da população e deu início ao movimento de oposição à monarquia que culminaria, em 1979, na Revolução Iraniana, sob o comando do Aiatolá Ruhollah Khomeini, (RIZWAN et al., 2014), gerando grandes mudanças para a região do Golfo Pérsico e o fim da aliança com os americanos.

A monarquia transformou-se numa república islâmica, seguindo os preceitos islâmicos xiitas, correspondendo à maioria religiosa da sociedade iraniana. O Irã passou a defender o movimento pan-arabista, além de buscar destronar as monarquia conservadoras (FADAEE, 2017) e espalhar a revolução pelo mundo árabe. Assim, o novo governo antiocidental e antimonárquico fez duras críticas às políticas e ações estadunidenses, ao Estado de Israel, devido sua expansão sobre território palestino e, às monarquias regionais, dentre elas a

${ }^{8}$ Como mencionado acima, tanto o Irã quanto a Arábia Saudita atuam na busca do poder e usam a religião e outras ferramentas para ganhar mais poder (FADAEE, 2017, p.20, tradução nossa). 
saudita, devido à relação da forma de governo com a religião islâmica. Teerã passou a se apresentar como a resistência islâmica e a liderança xiita, enquanto Riade mostrava-se como o centro religioso, por possuir as cidades de Meca e de Medina ${ }^{9}$, além de ser o grande poder sunita atrelado ao Ocidente.

Para Rizwan et al., "[t]he aggressive policies of the [Iranian] revolutionary government had isolated its [sic] from the regional and international community" (2014, p. 96) ${ }^{10}$. Nessas condições, os sauditas assumiram o posto de maior aliado americano no Golfo Pérsico, enquanto o Irã se isolou, pois, num contexto de Guerra Fria, sua possível aliada, a União Soviética, foi afastada pelo discurso revolucionário que condenava tanto comunistas como capitalistas. Além disso, os soviéticos também se sentiram ameaçados pelas possíveis revoltas islâmicas que poderiam ocorrer em seu território inspiradas pelos iranianos. As relações diplomáticas apenas pioraram entre os dois países, sendo interrompida entre os anos de 1988 e 1991, após as guerras entre Irã e Iraque e a invasão do Kuwait devido ao apoio saudita ao Estado iraquiano de Saddam Hussein.

Com a busca do Irã por uma maior inserção internacional, especialmente econômica, há uma reaproximação com a Arábia Saudita no início dos anos 2000. O país persa sofria com sanções impostas pelos Estados Unidos e outros países da União Europeia desde a Revolução de 1979 e, a assistência saudita seria de grande importância no contexto da OPEP para retomar as exportações de petróleo.

Após esse curto período, logo as relações entre os países islâmicos tornaram-se novamente complicadas. A "guerra ao terror" americana trouxe novamente conflitos para a região, e a entrada de Mahmoud Ahmadinejad na presidência do Irã em 2005 retomou uma linha considerada mais agressiva. A Arábia Saudita também assumiu uma postura mais hostil, acusando o Irã de ser uma ameaça devido ao seu programa nuclear, além de acusá-lo de interferir na política doméstica de Estados vizinhos - como o Bahrein e o Iêmen.

\section{Saída americana e Primavera Árabe}

Em 2011, o presidente estadunidense Barack Obama iniciou a retirada de suas tropas do solo iraquiano, findando a guerra após oito anos de conflito. Além de gerar um vácuo de poder na região do Golfo Pérsico, os Estados Unidos deixaram o Iraque destruído, com seus

\footnotetext{
${ }^{9}$ Cidades sagradas islâmicas localizadas em território saudita.

${ }^{10}$ As políticas agressivas do governo revolucionário iraniano isolaram o país da comunidade regional e internacional (2014, p. 96, tradução nossa).
} 
sistemas governamental e institucional debilitados e frágeis. Assim, o forte Estado iraquiano da época de Saddam Hussein tornou-se um Estado vulnerável, facilitando a entrada de influência de países vizinhos; e o fortalecimento ou surgimento de atores não estatais, como facções e grupos terroristas. O mesmo aplica-se ao Afeganistão, onde as tropas ianques começaram a reduzir seus números em 2012, porém a guerra no país ainda continua.

Nesse mesmo ano de 2011, tiveram início diversas manifestações e protestos em muitos países árabes (norte da África e Oriente Médio), para exigir reformas políticas e sociais, configurando a Primavera Árabe. Alguns países, principalmente as monarquias árabes, conseguiram controlar as manifestações e dar continuidade com seus governos, mesmo que enfraquecidos por não realizarem de forma completa as reformas exigidas. Esse enfraquecimento afetou diretamente o poder de barganha da Arábia Saudita na região, já que a maioria desses governos são sunitas e grandes aliados sauditas nas políticas referentes ao Golfo Pérsico.

O Egito, desde a retirada do presidente Hosni Mubarak em 2011, enfrentou problemas para estabelecer um novo governo. Com a ascensão da Irmandade Muçulmana nesse país, a Arábia Saudita vê-se sem um forte aliado seu, pois há grandes divergências em suas políticas. Já na Síria, as demonstrações inicialmente pacíficas transformaram-se numa guerra civil devido à bruta e violenta resposta de Bashar al-Assad às manifestações em 2011. A autoridade síria colapsou, deixando a população em péssimas condições e numa guerra que já dura sete anos. Os Estados Unidos assumiram uma política menos intervencionista no Oriente Médio, evitando participar da guerra. Da mesma forma que no Iraque, os governos desses países se encontram fracos, gerando os mesmos problemas já mencionados, porém de formas e intensidades diferentes.

Esses acontecimentos possibilitaram uma maior influência do Irã nesses países do Oriente Médio, por diversos motivos. As quedas de Saddam Hussein no Iraque e do Taliban no Afeganistão, as duas grandes ameaças para o governo de Teerã, contribuíram para o fortalecimento iraniano, ainda mais ao se considerar que ambos os países são de maioria xiita, colaborando com o discurso do sectarismo religioso, cada vez mais presente e mais forte nos conflitos do Golfo Pérsico.

O Irã é considerado o país ganhador (ou grande beneficiado) nas disputas mais recentes por influência na região do golfo quando se compara com a Arábia Saudita. Os motivos que podem ter contribuído para essa significativa escalada de poder no Golfo Pérsico são: a redução contínua do isolamento do país; o enfraquecimento de Estados vizinhos; e a 
mudança do comportamento iraniano ao buscar se inserir no sistema internacional. Ou seja, o Irã, apesar de considerado como rival saudita desde a revolução de 1979, detinha pouco poder, contrastando com os ganhos que começaram a surgir na metade dos anos 2000.

De acordo com Gause (2014), o vácuo de poder doméstico gerado pela quebra de autoridade e a fraqueza dos governos acabam por atrair poderes externos para que estes satisfaçam e alcancem seus objetivos e interesses. Entretanto, a construção de influências muitas vezes ocorre através de um sistema bottom-up (de baixo para cima), pois grupos e facções formados dentro do Estado débil buscam governos externos para apoio financeiro, militar e diplomático para suas causas, como ocorrido na Síria, Iraque e Iêmen - por exemplo.

Outro ponto importante é que esses vácuos de poder e essa fragilidade das instituições, além de facilitarem que outros países influenciem os mais fracos, também contribuem para o surgimento e o fortalecimento de atores não estatais filiados a questões religiosas ou étnicas, desafiando o monopólio da força que o Estado possui e seu domínio sobre o território. Além desses grupos mais voltados para questões políticas e sociais, há a formação de grupos paramilitares e extremistas, que às vezes recebem financiamento de outros Estados. Isso apenas aumenta a escala dos conflitos geopolíticos, contribuindo para um maior número de guerras "por procuração" em países vizinhos (KAUSCH, 2014). Na Síria e no Iraque, houve a ascensão do Estado Islâmico do Iraque e do Levante (EIIL) ${ }^{11}$, que chegaram a ocupar grandes áreas territoriais, controlando a produção e a venda de petróleo e a população local.

\section{Episódios mais recentes}

Em 2013, Hassan Rohani assumiu a presidência iraniana, fato que contribuiu para uma reaproximação com os países ocidentais, pois o atual presidente iraniano defende a realização eficaz de acordos com o Ocidente, além de sustentar, de forma sutil, uma separação entre religião e governo. Em 2015, foi assinado o acordo sobre o programa nuclear iraniano com as seis potências mundiais ${ }^{12}$, reduzindo consideravelmente as sanções estabelecidas em função tanto da corrida nuclear quanto da ocorrida revolução. Isso gerou insegurança por parte dos sauditas, já que a aproximação entre Estados Unidos e Irã criava a possibilidade de uma

\footnotetext{
${ }^{11} \mathrm{O}$ grupo extremista islâmico que ocupa territórios iraquianos e sírios, e que opera majoritariamente no Oriente Médio. O grupo é chamado por diferentes nomes. "Para autoridades da ONU e dos Estados Unidos, o grupo é o "Isil", um acrônimo em inglês para "Estado Islâmico do Iraque e do Levante" - que tem a versão também em português, "EIIL". O próprio grupo não usa esse nome desde junho de 2014, quando declarou a criação de um califado e reduziu seu nome para "Estado Islâmico" (com as siglas "IS" em inglês e "EI" em português), refletindo suas ambições expansionistas." (IRSHAID, 2017).

${ }^{12}$ Países do Conselho de Segurança da ONU (China, Estados Unidos, França, Reino Unido e Rússia) e Alemanha.
} 
inversão de alianças, ou seja, de um afastamento entre Washington e Riade - e uma posterior aproximação com Teerã. Entretanto, a entrada de Donald Trump no governo estadunidense a partir de 2017, e o suporte iraniano a Bashar al-Assad na guerra da Síria, dentre outros motivos, dificultaram a concretização dessa mudança de alianças.

In its desire to protect its domestic power base by eliminating potential external spoilers, Riyadh's long-term partnership with the United States has been built on the provision of US security guarantees in the Gulf in exchange for Saudi Arabia's ensuring the flow of oil at manageable prices. The relative US rapprochement with Iran, the announcement of America's "pivot to Asia", the dropping of long-term ally Hosni Mubarak, and US reluctance to intervene in Syria have all contributed to erode Riyadh's faith in the US as a stable, reliable ally. (KAUSCH, 2014, p.9) (13 $^{13}$

Somado a isso, sem as sanções, o Irã volta a se inserir na economia mundial, aumentando cada vez mais suas produções de petróleo. Este fato vem preocupando os sauditas, que receosos com este retorno iraniano, retardaram as negociações da OPEP visando aumentar o preço dos barris. Após quase um ano, no final de novembro de 2016, o acordo foi firmado, limitando a produção do Irã e reduzindo, apesar de pouco, a produção dos demais países. Devido a essas ameaças, o reino saudita aparenta buscar novas formas de manter seu poder sem precisar recorrer ao apoio ocidental ou ao dos Estados Unidos, diferente da política externa seguida tradicionalmente. (BARDAJÍ, 2016)

Novamente as relações diplomáticas com o Irã foram cortadas pela Arábia Saudita, que impeliu seus aliados a realizarem o mesmo no ano de 2016, após a invasão da embaixada saudita em Teerã, fato que ocorreu devido a protestos contra a execução do clérigo saudita de vertente xiita, Nimr Baqir al-Nimr. O clérigo foi uma importante figura durante os protestos realizados pela minoria xiita da Arábia Saudita contra o regime político do país durante a Primavera Árabe. Esta e outras execuções podem ser consideradas uma forma do rei saudita, recém-entronado, de demonstrar seu poder - que logo foi desafiado pelo governo catari, por retomar relações com o Irã em 2017.

Houve trocas de insultos entre as nações, nos quais o Irã acusou a Arábia Saudita de ser infiel e de apoiar movimentos terroristas e extremistas, além de utilizar formas violentas de repressão e adotar a pena de morte contra seus opositores internos. Ao mesmo tempo, o Irã foi acusado de não ser muçulmano, dado seu passado persa, além do fato de seguir a vertente

\footnotetext{
${ }^{13} \mathrm{Em}$ seu desejo de proteger sua base de poder doméstica eliminando possíveis problemas externos, a parceria de longos anos de Riade com os Estados Unidos foi construída com base na garantia dos EUA em prover segurança no Golfo em troca da Arábia Saudita garantir o fluxo de petróleo a preços gerenciáveis. A relativa aproximação dos EUA com o Irã; o anúncio americano do "pivô para a Ásia"; a queda do aliado de longa data Hosni Mubarak; e a relutância dos EUA em intervir na Síria contribuíram para desgastar a fé de Riade nos Estados Unidos como um aliado estável e confiável (KAUSCH, 2014, p.9, tradução nossa).
} 
xiita, o que significaria, para os sauditas um desvirtuamento da religião. De acordo com a Reuters (2017), era esperado que houvesse um encontro entre os governos após o Hajj ${ }^{14} \mathrm{em}$ setembro de 2017, porém até o momento, nenhuma melhora de diálogo entre iranianos e sauditas pôde ser observada.

Desde 2015, a Arábia Saudita vem apresentando mudanças em sua política externa com a ascensão ao trono do rei Salman bin Abdulaziz, que logo indicou um de seus filhos, Mohammed bin Salman (MBS) como o príncipe herdeiro, que se tornou o mais novo vice primeiro-ministro e ministro da defesa. Ao mesmo tempo em que a monarquia busca se reestruturar, também há a necessidade de realizar reformas socioeconômicas, de forma a reduzir a oposição que o governo saudita recebe, principalmente de minorias xiitas, e até mesmo de sua própria população.

A nova realidade geopolítica da região, especialmente com a retirada das tropas dos Estados Unidos, levou à criação de uma nova política externa, que faz parte de uma doutrina baseada em três pontos: reforçar o poder militar (buscando reduzir a dependência americana) e ser capaz de lidar com ameaças iranianas e terroristas; reavaliar alianças bilaterais e multilaterais, focando no Conselho de Cooperação do Golfo (CCG), Líbano e Egito; e confrontar a expansão iraniana de forma agressiva, mudando a postura saudita de reativa para proativa. Apesar da boa estratégia de Riade, sua execução até o momento não foi bem realizada, gerando resultados duvidosos, incoerentes e ineficientes, e provocando duras críticas e sérios problemas à imagem do país. Entretanto, do ponto de vista da monarquia, esses erros foram melhores do que não agir, assumindo, assim, uma política externa mais ativa sem a expectativa de obter um sucesso imediato, mas, sim, a longo prazo (Shihabi, 2017). Outra estratégia observada é a aproximação entre Israel e Arábia Saudita, que estão dispostos a cooperar e trocar informações e inteligência para confrontar o Irã.

[...] As previously stated, Saudi Arabia's concerns for security and relative gains lead it to maintain a covert partnership with Israel to balance against a rising Iran. Iran, in contrast, maintains a hostile relationship with Israel for reasons of power and identity given its goal for regional superiority, and its self-view as the liberator of the Muslim world. [...] Saudi Arabia's decision to covertly cooperate with Israel reveals its acknowledgement that overt cooperation would damage its reputation as the leader of Islam given Israel's unfavorable reputation in the Muslim world. The Saudi-Israeli covert

\footnotetext{
${ }^{14}$ Peregrinação religiosa para Meca que todos os seguidores do islã devem tentar realizar, pelo menos uma vez ao longo de suas vidas.
} 
partnership began developing when concerns over a nuclear Iran emerged. (HAMEED, 2017, p. 23) $)^{15}$

Já o governo de Teerã vem tendo um ano complicado em 2018, com a ocorrência de muitos protestos por todo o país, quer por questões sociais, econômicas ou culturais. Devido ao rígido sistema político iraniano, o presidente Rohani, juntamente com o parlamento, encontram limitações para realizarem mudanças e reformas mais radicais e necessárias. Esta dificuldade é proveniente do sistema religioso que rege a constituição do país. O líder supremo (Aiatolá), eleito de forma indireta, é a autoridade máxima política e religiosamente, além de controlar o judiciário, as forças armadas e ter grande influência na política externa, engessando qualquer ação de presidentes ou parlamentares que possuírem ideias divergentes ao do líder supremo. Atualmente, quem ocupa o cargo desde 1989 é o Aiatolá Ali Khamenei, que culpa o governo de Teerã de ser incompetente perante a crise que ronda o país, não apenas no âmbito interno - já que os Estados Unidos ameaçam acabar com o recente acordo nuclear. De acordo com Golkar (2018), a entrada de Rohani na presidência foi de encontro ao interesse de Khamenei, que buscava uma figura política moderada para negociar a retirada das sanções impostas ao Irã e o acordo nuclear com o Ocidente. Agora, o Aiatolá parece estar aumentando suas forças e poder política sob o setor militar, preparando-se para instaurar um governo militar quando necessário.

\section{Conclusão}

Os conflitos no Oriente Médio e a disputa pelo Golfo Pérsico encontram-se longe de chegar ao fim. As guerras na Síria e no Iêmen continuam, assim como a duvidosa luta contra os grupos terroristas na região, especialmente o EIIL; e, ao mesmo tempo, outros Estados precisam se reestruturar, buscando restabelecer a legitimidade e a força de seus governos e instituições, como Iraque e Egito. Esse estado regional relativamente caótico tende a fortalecer atores não estatais, como grupos sectários religiosos, étnicos e milícias, que apenas agravam a situação.

\footnotetext{
${ }^{15}$ Como dito anteriormente, as preocupações da Arábia Saudita com a segurança e os ganhos relativos levam-na a manter uma parceria encoberta com Israel para equilibrar com um Irã crescente. O Irã, em contraste, mantém um relacionamento hostil com Israel por razões de poder e identidade, dado seu objetivo de superioridade regional e sua visão de si mesmo como o libertador do mundo muçulmano. [...] A decisão da Arábia Saudita de cooperar secretamente com Israel revela seu reconhecimento de que a cooperação aberta prejudicaria sua reputação de líder do Islã, dada a reputação desfavorável de Israel no mundo muçulmano. A parceria secreta saudita-israelense começou a se desenvolver quando surgiram preocupações sobre um Irã nuclear (HAMEED, 2017, p. 23, tradução nossa).
} 
O cenário geopolítico do Golfo Pérsico continua tumultuado, permitindo manobras políticas tanto por parte da Arábia Saudita, quanto por parte do Irã. Na última década, fica evidente que os sauditas vêm sentindo-se cada vez mais ameaçados, não apenas pelo Irã, mas igualmente pelo distanciamento (mesmo que pequeno) dos Estados Unidos; e pela dificuldade de renovar sua forma de governo e influência, evitando revoltas e manifestações, como visto na Primavera Árabe - tanto domesticamente quanto em países aliados. Apesar disso, os sauditas ainda são detentores de grande influência na OPEP e no CCG, e vêm estruturando sua nova política externa, mais agressiva e ativa e menos dependente do Ocidente, para manter e expandir sua liderança, apesar de esta ainda não ter mostrado resultados satisfatórios.

Já para o Irã, o cenário regional mostra-se mais favorável. O enfraquecimento do Iraque e do Afeganistão contribuiu para Teerã expandir seu raio de influência, ao alcançar as maiorias xiitas desses países com maior facilidade. Além disso, a mudança para uma política externa menos agressiva, sem abandonar seu caráter antiamericano e anti-israelense, juntamente com a busca de uma maior internacionalização, foram fatores fundamentais para beneficiar o país persa. Entretanto, a retomada econômica vem enfrentando sérias dificuldades, como: sanções externas ainda existentes; a possível quebra do acordo nuclear com os Estados Unidos; retaliações e cortes de relações diplomáticas, influenciados pela disputa com os sauditas e por se envolver nos conflitos do golfo; e as recentes manifestações internamente.

Dessa forma, pode-se dizer que, nos últimos anos de disputa hegemônica no Golfo Pérsico, o Irã obteve melhores resultados que a Arábia Saudita, porém, não se pode afirmar que um detém mais poder do que o outro. Tanto o Golfo Pérsico como ambos os países ainda encontram-se em situações difíceis, que a qualquer momento podem modificar-se. As vitórias que cada um obteve, possuem uma contrapartida que as enfraquecem, principalmente no âmbito doméstico, que, ao necessitar maior ou menor atenção, influencia diretamente a direção que a política externa tomará. 


\section{Referências Bibliográficas}

BARDAJÍ, Rafael L. Religion, power and chaos in the Middle East. European View. Springer. Abril 2016. DOI 10.1007/s12290-016-0391-9.

CIFTCI, Sabri; TEZCÜR, Güneș Murat. Soft Power, Religion, and Anti-Americanism in the Middle East. Foreign Policy Analysis. Vol. 12, 2016. Pp. 374-394 DOI 10.1111/fpa.12090

FADAEE, Farshid. Iran and Saudi Arabia, and the Perfect Storm in the Persian Gulf. 2017. Dissertação mestrado. Departamennt of Peace and Conflict Research. Uppsala University. Primavera 2017.

GAUSE, F. Gregory, III. Beyond Sectarianism: The New Middle East Cold War. Brooking Doha Center Analysis Paper. Foreign Policy at Brookings. º11, Julho 2014.

GOLKAR, Saeid. Is a military coup possible in Iran? Al Jazeera, 24 abr. 2018. Disponível em: < https://www.aljazeera.com/indepth/opinion/military-coup-iran-180424144510759.html >. Acesso em: 28 abr. 2018.

HAMEED, Usjid U. The Saudi-Iranian Rivalry: A Foreign Policy Analysis Approach. Towson University Journal of International Affairs. Vol. L, $\mathrm{N}^{\circ} 2$, Towson University, Spring 2017. Pp. 16-34.

IRSHAID, Faisal. ISIS, Estado Islâmico ou Daesh? Um grupo extremista, muitos nomes. BBC Brasil, BBC Monitoring, 17 set. 2017. Disponível em: < http://www.bbc.com/portuguese/internacional-42020312>. Acesso em: 28 abr. 2018.

KAUSCH, Kristina. Competitve Multipolarity in the Middle East. IAI - Istituto Affari Internazionali. Setembro 2014. ISSN 2280-4341. Pp. 8-12

REUTERS STAFF. Iran, Saudi Arabia to exchange diplomatic visits: Iranian foreign minister. Reuters, 23 ago. 2017. Disponível em: <https://www.reuters.com/article/us-saudi-irandiplomacy/iran-saudi-arabia-to-exchange-diplomatic-visits-iranian-foreign-ministeridUSKCN1B31K8>. Acesso em: 13 mar. 2018.

RIZWAN, Muhammad; ARSHID, Muhammad; WAQAR, Muhammad; IRAM, Saira. From Rivalry to Nowhere: a Story of Iran-Saudi Ties. IOSR Journal of Humanities and Social Science. Vol. $19 \mathrm{~N}^{\circ} 9$ Ver. IV. Setembro 2014. Pp. 91-101.

SHIHABI, Ali. Saudi Arabias's new foreign policy doctrine. Arabia Foundation, 14 dez. 2017. Disponível em: < http://www.arabiafoundation.org/arabia-comment/saudi-arabias-newforeign-policy-doctrine/>. Acesso em: 28 abr. 2018. 